\title{
Oxygen-induced hypercapnia in COPD: myths and facts
}

\author{
Wilson F Abdo* and Leo MA Heunks
}

\begin{abstract}
During our medical training, we learned that oxygen administration in patients with chronic obstructive pulmonary disease (COPD) induces hypercapnia through the 'hypoxic drive' mechanism and can be dangerous. This mindset frequently results in the reluctance of clinicians to administer oxygen to hypoxemic patients with COPD. However, this fear is not based on evidence in the literature. Here, we will review the impact and pathophysiology of oxygen-induced hypercapnia in patients with acute exacerbation of COPD and recommend a titrated oxygen management.
\end{abstract}

In 1949, Davies and Mackinnon [1] described oxygeninduced neurological symptoms in patients with cyanosis due to emphysema with chronic cor pulmonale. After encountering two such cases, including one with a fatal coma, the authors set up a study to examine the effect of oxygen on intracranial pressure (that is, cerebrospinal fluid pressures measured through a lumbar puncture) in similar patients. The authors found that, in all four studied subjects with emphysema and cyanosis, oxygen therapy led to increased cerebrospinal fluid pressures, which returned to baseline when oxygen was stopped. Davies and Mackinnon hypothesized that oxygen intoxication could have led to accumulation of carbon dioxide $\left(\mathrm{CO}_{2}\right)$ in the body and cautioned against the use of oxygen in these patients. In response to this article, Donald [2] described an emphysema patient who developed a hypercapnic (16 kPa) coma during oxygen therapy and who had rapid clinical improvement after oxygen therapy was discontinued. The author, referring to such patients, stated the following theory: 'their

${ }^{*}$ Correspondence: f.abdo@ic.umcn.n

Department of Intensive Care Medicine, Radboud University Nijmegen Medical Center, Geert Grooteplein 10, PO BOX 9101, 6500 HB Nijmegen, The Netherlands respiratory activity depends mostly upon anoxic stimulation of the sino-aortic zones. The removal of the anoxic stimulus causes them to hypoventilate with further retention of carbon dioxide.'

Reading these early reports about oxygen-induced hypercapnia in patients with chronic obstructive pulmonary disease (COPD), one might think that not much has changed over the years. Despite subsequent studies and reviews [3] describing the effect of oxygen on the ventilator drive in patients with COPD, disproving the 'hypoxic drive' theorem, many clinicians are still being taught during their medical training that administration of oxygen in patients with COPD can be dangerous given that it induces hypercapnia through the 'hypoxic drive' mechanism; that is, increasing arterial $\mathrm{O}_{2}$ tension will reduce the respiratory drive, leading to a (dangerous) hypercapnia. This misconception has resulted in the reluctance of clinicians and nurses to administer oxygen to hypoxemic patients with COPD. In most cases, this is an unwise decision, putting at risk the safety of patients with acute exacerbation of COPD. In this concise paper, we will discuss the impact and pathophysiology of oxygen-induced hypercapnia in patients with acute exacerbation of COPD.

\section{Oxygen-induced hypercapnia}

In 1980, Aubier and colleagues [4] studied the effect of high-flow oxygen $\left(15 \mathrm{~L} /\right.$ minute) on arterial $\mathrm{CO}_{2}$ tension $\left(\mathrm{PaCO}_{2}\right)$ in patients with acute exacerbation of COPD (that is, Global Initiative for Chronic Obstructive Lung Disease (GOLD) grade IV). The authors found that $\mathrm{PaCO}_{2}$ increased from 8.4 to $11.4 \mathrm{kPa}$ but that arterial $\mathrm{O}_{2}$ tension $\left(\mathrm{PaO}_{2}\right)$ increased from 4.9 to $29 \mathrm{kPa}$. More than two decades later, this study was repeated [5]. In patients with very severe COPD (forced expiratory volume in 1 second (FEV1) $\pm 30 \%$ predicted), administration of $100 \%$ oxygen for 20 minutes increased $\mathrm{PaO}_{2}$ from 7.6 to $53 \mathrm{kPa}$ whereas $\mathrm{PaCO}_{2}$ showed a non-significant increase (6.9 and $7.3 \mathrm{kPa}$ ). Subsequently, patients were subdivided in a group of $\mathrm{CO}_{2}$ retainers and a group of non-retainers. Although the two groups had similar lung function, retainers were significantly more hypoxemic before oxygen administration. 
These and earlier studies confirmed that uncontrolled oxygen administration to patients with acute exacerbation of very severe COPD can induce hypercapnia and that the level of hypoxemia is a predictor for development of hypercapnia. Therefore, it is important to review the mechanisms of oxygen-induced hypercapnia in patients with COPD, in particular the role of oxygen-induced hypoventilation.

\section{The role of hypoventilation}

Figure 1 shows that uncontrolled oxygen administration leads to an early initial decrease in minute ventilation with an elevation of $\mathrm{PaCO}_{2}$ [4]. After 15 minutes of continued oxygen therapy, minute ventilation recovers from the initial decrease and is only marginally reduced in comparison with baseline. However, $\mathrm{PaCO}_{2}$ increases further despite the recovery of the minute ventilation. Additionally, no significant correlation was found between the oxygen-induced increase in $\mathrm{PaCO}_{2}$ and the reduction in minute ventilation. Formula 1 (below) can be used to show that, in this example, the change in minute ventilation explains a $\mathrm{PaCO}_{2}$ increase of only $0.65 \mathrm{kPa}$ (of the total rise of $3.0 \mathrm{kPa}$ ). Subsequent studies have essentially confirmed these observations [5]. In Formula $1, \mathrm{PaCO}_{2}=\left(\mathrm{K} \times \mathrm{V}_{\mathrm{CO} 2}\right) / \mathrm{V}_{\mathrm{E}}\left(1-\mathrm{V}_{\mathrm{D}} / \mathrm{V}_{\mathrm{T}}\right)$, where $\mathrm{K}$ is a constant of $0.863, \mathrm{~V}_{\mathrm{CO} 2}$ is $\mathrm{CO}_{2}$ production, $\mathrm{V}_{\mathrm{E}}$ is minute ventilation, and $\mathrm{V}_{\mathrm{D}} / \mathrm{V}_{\mathrm{T}}$ is dead space/tidal volume ratio.

In another study, Aubier and colleagues [6] studied the respiratory drive in 20 patients with both COPD and acute respiratory failure. The authors reported an increase in $\mathrm{PaCO}_{2}$ from 8.1 to $9.1 \mathrm{kPa}$ and a marginal (14\%) reduction in minute ventilation on oxygen administration [6]. Respiratory drive was determined by mouth occlusion pressure in the first $100 \mathrm{~ms}$ of inspiratory effort $\left(\mathrm{P}_{0.1}\right)$. Oxygen administration reduced $\mathrm{P}_{0.1}$ from $8.3 \pm 0.8 \mathrm{~cm} \mathrm{H}_{2} \mathrm{O}$ to $4.9 \pm 0.7 \mathrm{~cm} \mathrm{H}_{2} \mathrm{O}$. The latter value is still well above normal, indicating a high respiratory drive. Moreover, the authors showed that there was no correlation between change in minute ventilation and change in $\mathrm{PaCO}_{2}$ after oxygen administration. This study underscores the markedly increased respiratory drive in patients during an exacerbation of COPD, even after oxygen administration, despite an increase in $\mathrm{PaCO}_{2}$. The authors concluded that reduction in respiratory drive is not a major contributor to oxygeninduced hypercapnia in patients with acute exacerbation of COPD.

In conclusion, uncontrolled oxygen administration in acute exacerbation of severe COPD has a limited effect on minute ventilation and thus does not explain the total increase in $\mathrm{PaCO}_{2}$. Rarely, one might encounter an apneic response in decompensated COPD patients approaching hypercapnic coma.

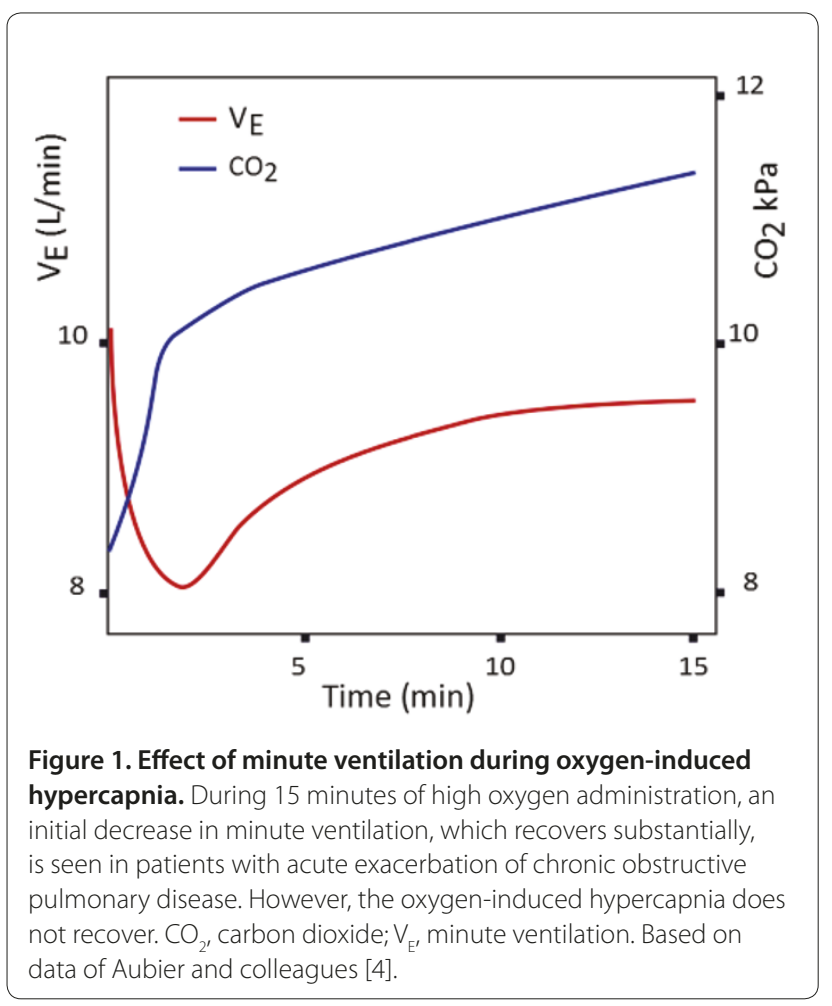

\section{The role of ventilation-perfusion mismatching}

Physiologically, alveolar ventilation and perfusion are well matched. Two extremes of ventilation-perfusion $(\mathrm{Va} / \mathrm{Q})$ mismatch may occur: (a) no ventilation of an alveolus but adequate perfusion, resulting in shunting, and (b) adequate ventilation but no perfusion, resulting in dead space ventilation. The body has protective mechanisms to optimize the Va/Q ratio. When alveolar oxygen tension decreases (for example, in bronchoconstriction), local mediators induce vasoconstriction of pulmonary capillaries supporting this particular alveolus, counteracting possible shunting, a mechanism called hypoxic pulmonary vasoconstriction (Figure 2). The strongest mediator for hypoxic pulmonary vasoconstriction is alveolar $\mathrm{pO}_{2}$ (partial pressure of oxygen). Therefore, a high fraction of inspired $\mathrm{O}_{2}\left(\mathrm{FiO}_{2}\right)$ will increase $\mathrm{O}_{2}$ tension in alveoli with a low level of ventilation, inhibiting hypoxic pulmonary vasoconstriction. As a result, alveoli with relatively impaired ventilation are well perfused, leading to an increase in $\mathrm{Va} / \mathrm{Q}$ mismatch. Indeed, the study by Aubier and colleagues [4] revealed that high $\mathrm{FiO}_{2}$ impaired $\mathrm{Va} / \mathrm{Q}$ matching and increased dead space ventilation from $77 \%$ to $82 \%$. Robinson and colleagues [5] also studied the Va/Q mismatch during oxygen therapy. The Va/Q mismatch increased in both the retainer and non-retainer groups of patients. The authors also concluded that this was due to less hypoxic pulmonary vasoconstriction in both groups. Although overall 


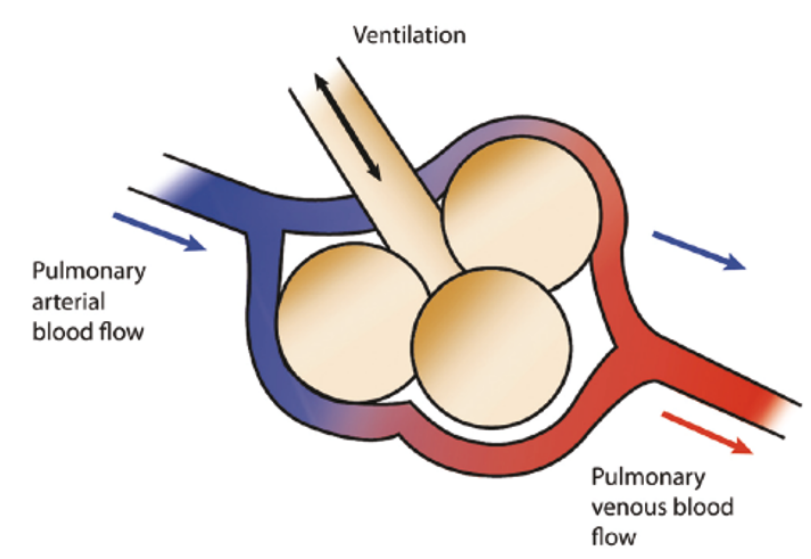

Figure 2. Hypoxic pulmonary vasoconstriction. The left frame shows normal alveolar ventilation and perfusion. In the right frame, reduced ventilation (thus $\mathrm{O}_{2}$ tension) in the alveolus (green) leads to a reduced perfusion because of the hypoxic pulmonary vasoconstriction mechanism. Reprinted with permission from BMJ Publishing Group Ltd and Royal College of Paediatrics and Child Health [13].

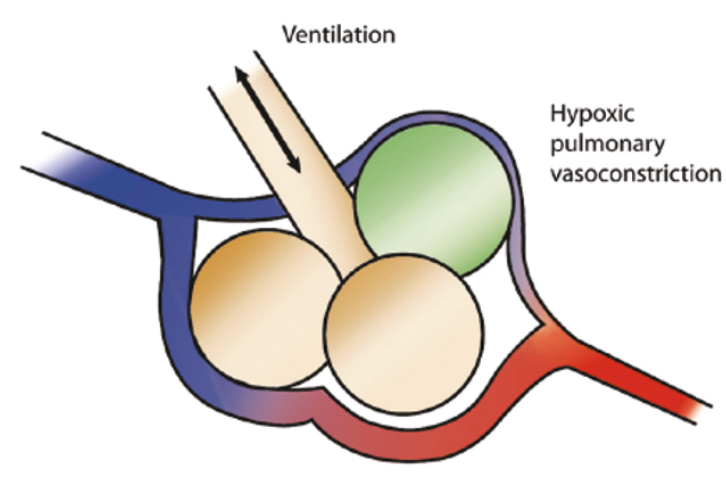

ventilation decreased in the retainer group, ventilation to lung units with higher $\mathrm{Va} / \mathrm{Q}$ mismatch increased, leading to increased alveolar dead space ventilation in the retainer group. An earlier report using a computer model to simulate pulmonary circulation found that the increased physiologic dead space through worsened Va/ $\mathrm{Q}$ was sufficient to account for the oxygen-induced hypercapnia [7].

\section{The Haldane effect}

Amine groups of proteins, in particular hemoglobin, combine with $\mathrm{CO}_{2}$ to form carbamino compounds. But the ability of deoxygenated hemoglobin to bind $\mathrm{CO}_{2}$ is much higher than that of oxygenated hemoglobin, as can be shown with Formula 2 (below). Thus, oxygen induces a rightward shift of the $\mathrm{CO}_{2}$ dissociation curve and this is known as the Haldane effect. A rightward shift in the $\mathrm{CO}_{2}$ dissociation curve will increase $\mathrm{PaCO}_{2}$, which normally is excreted through elevated minute ventilation, normalizing $\mathrm{PaCO}_{2}$. However, in patients with severe COPD, who are unable to increase minute ventilation, the Haldane effect will increase $\mathrm{PaCO}_{2}$. Indeed, in the study by Aubier and colleagues [4], the Haldane effect explained $\pm 25 \%$ of the total $\mathrm{PaCO}_{2}$ increase due to $\mathrm{O}_{2}$ administration. Formula 2 is $\mathrm{HbCO}_{2} \leftrightarrow \mathrm{O}_{2} \times \mathrm{HbO}_{2}+$ $\mathrm{PaCO}_{2}$, where $\mathrm{HbCO}_{2}$ is carbaminohemoglobin and $\mathrm{HbO}_{2}$ is oxyhemoglobin.

\section{Safe oxygen administration}

Patients most susceptible to oxygen-induced hypercapnia are those with the most severe hypoxemia. How can oxygen-induced hypercapnia be avoided without withholding oxygen therapy from these hypoxemic patients? Administration of high-flow oxygen concentrations has been associated with higher mortality in comparison with a more tailored approach of oxygen therapy [8-10]. Some data, including those of a randomized controlled trial, provide evidence for the best strategy in patients with an acute exacerbation of COPD [11]. These data show that a titrated oxygen administration to achieve an oxygen saturation of between the $88 \%$ to $92 \%$ compared with higher saturations results in less respiratory acidosis and better outcome. This is in accordance with the British Thoracic Society guideline for oxygen therapy in patients with COPD [12].

\section{Conclusions}

In patients with COPD, hypoxic pulmonary vasoconstriction is the most efficient way to alter the $\mathrm{Va} / \mathrm{Q}$ ratios to improve gas exchange. This physiological mechanism is counteracted by oxygen therapy and accounts for the largest increase of oxygen-induced hypercapnia. A titrated oxygen therapy to achieve saturations of $88 \%$ to $92 \%$ is recommended in patients with an acute exacerbation of COPD to avoid hypoxemia and reduce the risk of oxygen-induced hypercapnia.

\section{Abbreviations}

$\mathrm{CO}_{2}$, carbon dioxide; $\mathrm{COPD}$, chronic obstructive pulmonary disease; $\mathrm{FiO}_{2}$ fraction of inspired oxygen; $P_{0.1}$, mouth occlusion pressure in the first $100 \mathrm{~ms}$ of inspiratory effort; $\mathrm{PaCO}_{2}$, arterial partial pressure of carbon dioxide; $\mathrm{PaO}_{2^{\prime}}$ arterial partial pressure of oxygen; $\mathrm{Va} / \mathrm{Q}$, ventilation-perfusion.

\section{Competing interests}

The authors declare that they have no competing interests.

Published: 29 October 2012

\section{References}

1. Davies $C E$, Mackinnon J: Neurological effects of oxygen in chronic cor pulmonale. Lancet 1949, 2:883-885.

2. Donald K: Neurological effects of oxygen. Lancet 1949, 2:1056-1057.

3. Milic-Emili J, Aubier M: Some recent advances in the study of the control of 
breathing in patients with chronic obstructive lung disease. Anesth Analg 1980, 59:865-873.

4. Aubier M, Murciano D, Milic-Emili J, Touaty E, Daghfous J, Pariente R, Derenne JP: Effects of the administration of $\mathrm{O} 2$ on ventilation and blood gases in patients with chronic obstructive pulmonary disease during acute respiratory failure. Am Rev Respir Dis 1980, 122:747-754.

5. Robinson TD, Freiberg DB, Regnis JA, Young $\mathrm{H}$ : The role of hypoventilation and ventilation-perfusion redistribution in oxygen-induced hypercapnia during acute exacerbations of chronic obstructive pulmonary disease. Am J Respir Crit Care Med 2000, 161:1524-1529.

6. Aubier M, Murciano D, Fournier M, Milic-Emili J, Pariente R, Derenne JP. Central respiratory drive in acute respiratory failure of patients with chronic obstructive pulmonary disease. Am Rev Respir Dis 1980, 122:191-199.

7. Hanson CW, III, Marshall BE, Frasch HF, Marshall C: Causes of hypercarbia with oxygen therapy in patients with chronic obstructive pulmonary disease. Crit Care Med 1996, 24:23-28.

8. Denniston AK, O'Brien C, Stableforth D: The use of oxygen in acute exacerbations of chronic obstructive pulmonary disease: a prospective audit of pre-hospital and hospital emergency management. Clin Med 2002, 2:449-451.
9. Durrington HJ, Flubacher M, Ramsay CF, Howard LS, Harrison BD: Initial oxygen management in patients with an exacerbation of chronic obstructive pulmonary disease. QJM 2005, 98:499-504

10. Wijesinghe M, Perrin K, Healy B, Hart K, Clay J, Weatherall M, Beasley R: Prehospital oxygen therapy in acute exacerbations of chronic obstructive pulmonary disease. Intern Med J 2011, 41:618-622.

11. Austin MA, Wills KE, Blizzard L, Walters EH, Wood-Baker R: Effect of high flow oxygen on mortality in chronic obstructive pulmonary disease patients in prehospital setting: randomised controlled trial. BMJ 2010, 341:c5462.

12. O'Driscoll BR, Howard LS, Davison AG: BTS guideline for emergency oxygen use in adult patients. Thorax 2008,63 (Suppl 6):vi1-68.

13. Dhillon R: The management of neonatal pulmonary hypertension. Arch Dis Child Fetal Neonatal Ed 2012, 97:F223-228.

doi:10.1186/cc11475

Cite this article as: Abdo WF, Heunks LMA: Oxygen-induced hypercapnia in COPD: myths and facts. Critical Care 2012, 16:323. 